\title{
Analisis dan Perhitungan Pengaruh Bilangan Raynolds Terhadap Kinerja Kondensor Tipe Concentric Tube Sebagai Alat Pengujian dan Pembelajaran
}

\author{
Analysis and Evaluation at the Effect of Raynolds Numbers on the Performance \\ of Concentric Tube Type Condensers for Testing and Learning Tools
}

\author{
Sobar Ikhsan \\ Fakultas Teknik, Prodi Teknik Mesin Universitas Islam \\ Kalimantan MAB \\ sobar.uniska@gmail.com
}

\author{
Heri Irawan \\ Fakultas Teknik, Prodi Teknik Mesin Universitas Islam \\ Kalimantan MAB \\ heri.irawan.up@gmail.com
}

\begin{abstract}
Abstrak--Kondensor yang dipakai pada industri kecil umumnya sederhana, yang mana hanya terkontruksi dari dua buah pipa yang konsentrik saja., maka dalam penelitian ini dibuat suatu design kondensor yang dapat meningkatkan kapasitas. Sehingga dapat diketahui berapa besarnya kapasitas kondensat; daya pompa; nilai koefisien perpindahan menyeluruh pada variasi Reynold yaitu 8000, 12000, 25000, 48000 dan 64000 serta kinerja dari kondensor Dalam penelitian ini digunakan model kondensor tipe concentric tube, untuk bahan shell digunakan baja karbon dengan diameter dalam $22,9 \mathrm{~mm}$, diameter luar $25,4 \mathrm{~mm}$, dan panjang $400 \mathrm{~mm}$. Untuk bahan tube dipakai tembaga dengan diameter dalam $13,4 \mathrm{~mm}$, diameter luar $15,9 \mathrm{~mm}$, dan panjang $2000 \mathrm{~mm}$.

Berdasarkan hasil analisis perhitungan didapatkan bahwa dengan perubahan variasi bilangan Reynolds yang semakin besar maka kapasitas kondensat, daya pompa, dan koefisien perpindahan menyeluruhnya juga cenderung meningkat. untuk bilangan Reynolds 8000, 12000, 25000, 48000, dan 64000. besarnya harga koefisien perpindahan panas menyeluruh adalah $24.48,31.74,52.07,82.66$ dan $101.89 \mathrm{~W} / \mathrm{m}^{2} \mathrm{~K}$, dan untuk besarnya daya pompa yang dibutuhkan sebesar 28617, 28405, 28904 dan 29362 Watt, masing-masing untuk setiap variasi bilangan Reynolds.
\end{abstract}

Kata kunci: kondensor, concentric tube, bilangan Reynolds

Abstract--Condensers used in small industries are generally simple, which is only constructed from two concentric pipes only, so in this study a condenser design is made that can increase capacity. So that it can be known how much condensate capacity is; pump power; Overall displacement coefficient value on Reynold variation of 8000, 12000, 25000, 48000 and 64000 and performance of condenser.

In this study used a concentric tube type condenser model, for shell material used carbon steel with an inner diameter of $22.9 \mathrm{~mm}$, an outer diameter of $25.4 \mathrm{~mm}$, and a length of $400 \mathrm{~mm}$. Copper is used for tube material with an inner diameter of $13.4 \mathrm{~mm}$, an outer diameter of $15.9 \mathrm{~mm}$, and a length of $2000 \mathrm{~mm}$.
Based on the results of the calculation analysis, it was found that with the greater variation in Reynolds number, the condensate capacity, pump power and overall displacement coefficient also increased. for Reynolds numbers 8000, 12000, 25000, 48000, and 64000. the total price of the overall heat transfer coefficients is $24.48,31.74,52.07,82.66$ and $101.89 \mathrm{~W} / \mathrm{m} 2 \mathrm{~K}$, and for the required pump power of 28617, 28405, 28904 and 29362 Watt, each for each variation of the Reynolds number.

Key words: condenser, concentric tube, Reynolds number

\section{PENDAHULUAN}

Kondensor merupakan komponen pendingin yang sangat penting yang berfungsi untuk memaksimalkan efisiensi pada mesin pendingin,. Pada kondensor ini, terjadi pelepasan kalor secara kondensasi dan kalor sensibel. Pada umumnya menggunakan kondensor tipe permukaan (surface condenser), tipe kondensor ini merupakan jenis shell-tube yang mana air pendingin disirkulasikan melalui tube. Kondensor biasanya menggunakan sirkulasi air pendingin dari menara pendingin (cooling tower) untuk melepaskan kalor ke atmosfir, atau once-through water dari sungai, danau atau laut.

Kebanyakan aliran fluida kerja yang mengalir secara terus menerus di dalam alat penukar kalor (APK), setelah melampaui waktu operasi tertentu akan mengotori permukaan perpindahan panasnya. Deposit yang terbentuk di permukaan kebanyakan akan mempunyai konduktivitas termal yang cukup rendah sehingga akan mengakibatkan menurunnya besaran koefisien global perpindahan panas di dalam alat penukar kalor, akibatnya laju pertukaran energi panas di dalam APK menjadi lebih rendah.

Dasar perhitungan desain termal kondensor adalah terpenuhinya kinerja secara termal pada kondisi normal. Berbagai asumsi dapat diambil untuk penyelesaian dengan menentukan kondensor sebagai volume control tunggal (single 
control volume) dan rerata koefisien transfer kalor dua sisimasuk dan keluar. Koefisien transfer kalor didasarkan pada konstituen koefisien sisi-shell (kondensasi) dan sisi-tube (pendingin).

Proses perubahan uap menjadi cair atau kondensasi berlangsung di dalam bak, dimana fluida uap mengalir di dalam pipa dan fluida dingin berada di luar pipa atau berada di dalam bak, aliran fluida dingin yang mengalir ke dalam bak dipengaruhi oleh gaya gravitasi yang mengalir secara alami dari mata air. Sirkulasi fluida dingin yang digunakan untuk pendinginan langsung dibuang ke sungai, sehingga fluida dingin membutuhkan jumlah yang banyak. Jadi apabila proses penyulingan dilakukan di daerah yang kekurangan air, maka proses penyulingan tidak dapat dilakukan.

Untuk memperoleh performan yang sebaik-baiknya maka alat penukar kalor harus dirancang dengan cara yang seksama dan seoptimal mungkin. Oleh karena itu penguasaan metode perancangan sebuah alat penukar kalor menjadi sangat penting karena akan memberikan kontribusi yang sangat besar kepada upaya peningkatan performance instalasi industri, yang berarti juga kepada upaya penghematan energi terutama di sektor industri

\section{BAHAN DAN METODA}

Alat yang diteliti adalah Unit Model Heat Exchanger Concentric Tube Posisi Horizontal seperti pada Gambar 1

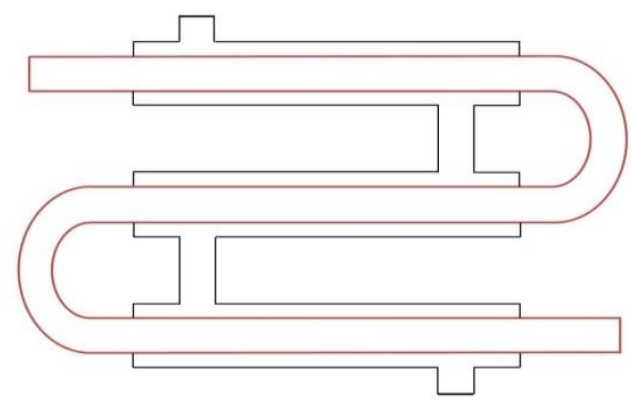

Gambar.1 Model Heat Exchanger Concentric Tube

Pipa tembaga dengan panjang $2000 \mathrm{~mm}$, diameter luar 15,9 $\mathrm{mm}$ dan diameter dalam 13,4 mm, yang digunakan sebagai tube. Pipa stainless dengan panjang $400 \mathrm{~mm}$, diameter luar $25,4 \mathrm{~mm}$ dan diameter dalam $22,9 \mathrm{~mm}$, yang digunakan sebagai shell

Data - data yang dibutuhkan dalam penelitian ini adalah data desain dari kondensor tipe Concentric Tube pada mesin. Metode penelitian yang dipilih adalah metode eksperimen pada desain alat penukar kalor dengan menggunakan persamaan-persamaan teoritis.

Pengujian dilakukan untuk aliran berlawanan dengan 5 macam variabel bilangan Reynolds yaitu 8000, 12000, 25000, 48000 dan 64000. Data-data yang diambil adalah temperatur masuk fluida panas $\left(\mathrm{T}_{\mathrm{h}, \mathrm{i}}\right)$, temperatur masuk fluida dingin $\left(\mathrm{T}_{\mathrm{c}, \mathrm{i}}\right)$, temperatur keluar fluida panas $\left(\mathrm{T}_{\mathrm{h}, \mathrm{o}}\right)$, temperatur keluar fluida dingin $\left(\mathrm{T}_{\mathrm{c}, \mathrm{o}}\right)$, temperatur luar pipa tembaga ( $\mathrm{T}_{\mathrm{W}, \text { luar}}$, temperatur dalam pipa tembaga ( $\left.\mathrm{T}_{\mathrm{W}, \text { dalan }}\right)$, hasil kondensat $\left(\mathrm{V}_{\mathrm{kond}}\right)$, dan tekanan air..

\section{HASIL DAN PEMBAHASAN}

Pada bagian ini akan dilakukan perhitungan awal desain alat penukar kalor tipe concentric tube dengan tujuannya adalah menentukan dimensi utama dari alat penukar kalor, yaitu luas permukaan total $\left(\boldsymbol{A}_{\text {total }}\right)$ perpindahan panas yang diperlukan oleh alat tersebut sesuai dengan beban termal yang diberikan sesuai dengan kondisi awal dari alat tersebut.

Data awal kondisi operasi yang diberikan untuk alat penukar kalor kondensor tipe concentric tube sebagai berikut: Temperatur udara masuk $\left(T_{c i}\right) 30^{\circ} \mathrm{C}$, Temperatur udara keluar $\left(T_{c o}\right) 55^{\circ} \mathrm{C}$, Spesifik heat udara $\left(C_{p c}\right) 1014 \mathrm{j} / \mathrm{kg}$, Temperatur gas masuk $\left(T_{h i}\right) 150{ }^{\circ} \mathrm{C}$, Temperatur gas keluar $\left(T_{h o}\right) 115{ }^{\circ} \mathrm{C}$, Spesifik heat gas $\left(C_{p h}\right) 1047 \mathrm{j} / \mathrm{kg}$, Laju aliran massa gas 20.8 $\mathrm{kg} / \mathrm{s}$ Diameter luar shell $\left(\mathrm{D}_{\mathrm{O}}\right)$ 0,0254 m Diameter shell $\left(\mathrm{D}_{\mathrm{i}}\right)$ 0,0229 m, Diameter luar tube $\left(\mathrm{d}_{\mathrm{O}}\right)$ 0,0159 m, Diameter dalam tube $\left(\mathrm{d}_{\mathrm{i}}\right)$ 0,0134 $\mathrm{m}$, Panjang penukar kalor (L) $2 \mathrm{~m}$

Hasil bilangan Reynold menunjukan bahwa fluida dingin semakin besar maka kapasitas aliran fluida panas akan semakin besar. Peningkatan kapasitas aliran fluida panas disebabkan karena semakin besar bilangan Reynolds maka koefisien perpindahan panas menyeluruh juga akan semakin besar, sehingga menyebabkan proses perpindahan kalor dari fluida. Panas ke fluida dingin berlangsung dengan cepat. Selain itu peningkatan kapasitas kondensat disebabkan karena semakin berkurangnya debit air yang berada di dalam bejana akibat dari pemanasan yang berlangsung, sehingga menyebabkan produksi uap yang dihasilkan semakin bertambah. Dari hasil eksperimen dengan bilangan Reynolds fluida dingin 2760 besarnya kapasitas aliran fluida panas adalah $2,3004 \times 10^{-3} \mathrm{~kg} / \mathrm{s}$, begitu juga dengan bilangan Reynolds 8000, 12000, 25000, 48000, dan 64000. terjadi peningkatan kapasitas aliran fluida panas. Sehingga kapasitas aliran fluida panasnya menjadi $2,2948 \times 10^{-3}$; $2,449 \times 10^{-3} ; 2,468 \times 10^{-3}$; dan $2,5742 \times 10^{-3} \mathrm{~kg} / \mathrm{s}$. Dimana kapasitas kondensat diambil dari nilai rata-rata hasil kapasitas aliran fluida panas.

Semakin besar bilangan Reynolds fluida dingin maka besarnya koefisien perpindahan panas menyeluruh akan semakin meningkat. Peningkatan harga koefisien perpindahan panas menyeluruh terjadi karena semakin besar bilangan Reynolds maka bentuk aliran yang terjadi di dalam shell akan semakin tak beraturan, sehingga proses perpindahan kalor dari fluida dingin yang menyerap kalor fluida panas akan semakin cepat dengan gerakan aliran yang semakin tidak seragam sebagaimana ditunjukkan Gambar 2. Dari hasil perhitungan untuk bilangan Reynolds 8000, 12000, 25000, 48000, dan 64000. besarnya harga koefisien perpindahan panas menyeluruh adalah 24.48, 31.74, 52.07, 82.66 dan $101.89 \mathrm{~W} / \mathrm{m}^{2} \mathrm{~K}$. Dimana harga koefisien 
perpindahan panas menyeluruh di ambil dari nilai ratarata eksperimen

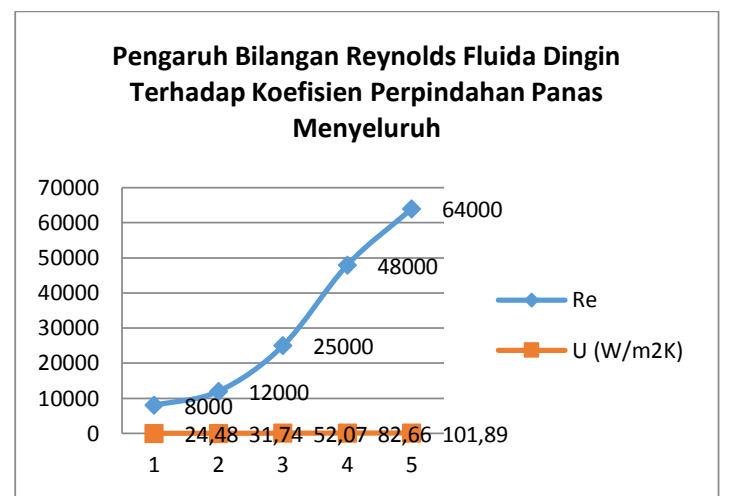

Gambar 2. Pengaruh Bilangan Reynolds Fluida Dingin Terhadap Koefisien Perpindahan Panas Menyeluruh

Hubungan antara bilangan Reynolds fluida dingin dengan daya pompa ditunjukkan Gambar 3, dimana semakin besar bilangan Reynolds fluida dingin maka daya pompa yang dibutuhkan untuk mengalirkan fluida dingin juga semakin besar.

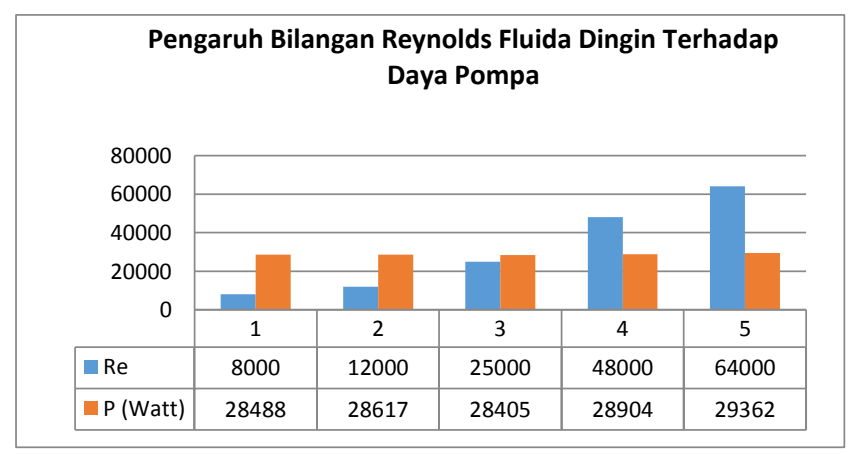

Grafik 3. Pengaruh Daya Pompa Terhadap Kapasitas Aliran Fluida Panas

Dari hasil analisis perhitungan didapatkan pada daya pompa 28488 Watt menghasilkan kapasitas aliran fluida panas sebanyak 0,0023004 kg/s, pada daya 28617 Watt menghasilkan $0,002294 \mathrm{~kg} / \mathrm{s}$, pada daya 28405 Watt menghasilkan $0,002449 \mathrm{~kg} / \mathrm{s}$, pada daya 28904 Watt menghasilkan $0,002468 \mathrm{~kg} / \mathrm{s}$ dan pada daya 29362 Watt menghasilkan kapasitas aliran fluida panas sebesar 0,002574 $\mathrm{kg} / \mathrm{s}$. Dimana harga daya pompa dan kapasitas aliran fluida panas diambil dari nilai rata-rata eksperimen.

\section{KESIIMPULAN}

Berdasarkan analisis data dan pembahasan, dapat diambil kesimpulan mengenai alat penukar kalor model kondensor tipe concentric tube sebagai berikut :

1. Semakin besar bilangan Reynolds fluida dingin maka besarnya koefisien perpindahan panas menyeluruh akan semakin meningkat. Peningkatan harga koefisien perpindahan panas menyeluruh terjadi karena semakin besar bilangan Reynolds maka bentuk aliran yang terjadi di dalam shell akan semakin tak beraturan, sehingga proses perpindahan kalor dari fluida dingin yang menyerap kalor fluida panas akan semakin cepat dengan gerakan aliran yang semakin tidak seragam. Dari hasil perhitungan untuk bilangan Reynolds 8000, 12000, 25000, 48000, dan 64000. besarnya harga koefisien perpindahan panas menyeluruh adalah 24.48, 31.74, 52.07, 82.66 dan $101.89 \mathrm{~W} / \mathrm{m}^{2} \mathrm{~K}$. Dimana harga koefisien perpindahan panas menyeluruh di ambil dari nilai rata-rata eksperimen.

2. Hubungan antara bilangan Reynolds fluida dingin dengan daya pompa, dimana semakin besar bilangan Reynolds fluida dingin maka daya pompa yang dibutuhkan untuk mengalirkan fluida dingin juga semakin besar. Dari hasil perhitungan diketahui bahwa dengan bilangan Reynolds fluida dingin 8000 daya pompa yang dibutuhkan sebasar 28488 Watt, begitu juga dengan bilangan Reynolds fluida dingin 12000, 25000, 48000, dan 64000. besarnya daya pompa yang dibutuhkan sebesar 28617, 28405, 28904 dan 29362 Watt.

3. daya pompa terhadap kapasitas aliran fluida panas terlihat bahwa semakin besar daya pompa maka kapasitas aliran fluida panas yang dihasilkan juga semakin banyak. Hal ini berhubungan dengan unjuk kerja pompa, dimana seiring dengan peningkatan daya pompa unjuk kerja pompapun juga meningkat sehingga berpengaruh pada peningkatan kapasitas aliran fluida panas. Dari hasil analisis perhitungan didapatkan pada daya pompa 28488 Watt menghasilkan kapasitas aliran fluida panas sebanyak $0,0023004 \mathrm{~kg} / \mathrm{s}$, pada daya 28617 Watt menghasilkan $0,002294 \mathrm{~kg} / \mathrm{s}$, pada daya 28405 Watt menghasilkan $0,002449 \mathrm{~kg} / \mathrm{s}$, pada daya 28904 Watt menghasilkan $0,002468 \mathrm{~kg} / \mathrm{s}$ dan pada daya 29362 Watt menghasilkan kapasitas aliran fluida panas sebesar $0,002574 \mathrm{~kg} / \mathrm{s}$. Dimana harga daya pompa dan kapasitas aliran fluida panas diambil dari nilai rata-rata eksperimen

\section{UCAPAN TERIMA KASIH}

Pada kesempatan ini, saya mengucapkan terima kasih yang tak terhingga kepada:

1. Kepada DPRM Kemenristek Dikti yang telah membiayai penelitian ini.

2. Ketua LPPM Uniska MAB yang senantiasa mengarahkan dan membimbing dalam proses pelaksanaan penelitian hingga laporan ini.

3. Bapak M. Firman, ST., MT selaku Kepala Lab. Program Studi Teknik Mesin, Universitas Islam Kalimantan MAB.

4. Kedua orang tua saya, yang telah memberikan energi yang sangat laur biasa.

\section{DAFTAR PUSTAKA}

[1] Prayito, Danu Edi, 2018, Perancangan Alat Kumbu Bakpia Di Kelompok Wanita Tani "Rahayu” Bangunharjo, Program Studi Teknik Industri, Universitas Teknologi Yogyakarta.

[2] Pahl. G., and Beitz, W. 2007, Engineering Design: Systematic Approach, $3^{\text {rd }}$ Edition, Springer Verlag, Berlin. 
[3] Kannengeisser, U., da J.A. Gero, A Comparison Between Pahl And Beitz' Systematic Approach and The Design Behaviour Of Mechanical Engineering Students.

Tersedia di http://mason.gmu.edu/ jgero/publications/Progress/15KannengiesserGe ro.EmpiricalSupport.pdf, diakses tanggal 21 Desember 2018.

[4] Motte, D., 2008, A Review of The Fundamentals of Systematic Engineering Design Process Models, International Design Conference Design, Croatio,.

[5] Mendes, L. A., Back, N., and Oliveira, G. H. C., 2009, Designing automated test systems: An adapted methodology inspired on Pahl and Beitz's Systematic Approach, Robotics and Computer-Integrated Manufacturing, 25(6):pp. 945-950,

[6] Weiss, M, and Hari, A., 2015, Extension of the Pahl \& Beitz systematic method for conceptual design of a new product, Procedia CIRP 36, pp. $254-260$,
[7] Nursyahuddin, D., dan D. Gasni, 2014, Proses Perancangan Sistem Mekanik dengan Pendekatan Terintegrasi: Studi Kasus Perancangan Alat Uji Pin on Disc, TeknikA, Vol. 21, No. 1, Hal 14-29.

[8] Effendi, I.A, dan Ade Ramdan, 2014, Apllkasi Metode Perancangan Pahl-Beitz pada Perancangan Lini Produksi, Prosiding Seminar Nasional Teknologi Manufaktur Bandung.

[9] Putra, W. W., Redesain Meja dan Kursi Siswa di Yaketunis Yogyakarta, Invensi, Vol. 3, No. 1, 2018.

[10] Kamarudin, 2015, Modelling the Conceptual Design Process with Hybridization of TRIZ Methodology and Systematic Design Approach, Procedia Engineering 131, pp.1064 - 1072. 